\title{
Die voorspelling van kredietrisiko met behulp van biografiese veranderlikes - Is dit die antwoord?
}

\author{
P.L.S. Ackermann \\ Skool van Bedryfsleiding, Universiteit van Suid-Afrika, Pretoria
}

\author{
W.P. Jansen van Rensburg \\ Trust Bank Hoofkantoor, Johannesburg
}

\begin{abstract}
The prediction of credit risk by means of blographic variables b this the anower? The objective of this study is to identity specific biographical variables, to quantify them and to investigate their relative importance in the prediction of credit risk. A representative sample of 250 bad credit risk clients and 250 good credit risk clients is used in the study. A multiple stepwise regression analysis and multiple stepwise discriminant analysis were carried out. Nine biographical variables were identified which explain approximately $16 \%$ of the variance of credit risk.

S. Afr. J. Bus. Mgmt. 1983, 14: $166-171$
\end{abstract}

Die doel van die ondersoek is om bepaalde biografiese veranderlikes te identifiseer, te kwantifiseer en die relatiewe belangrikheid daarvan by die voorspelling van kredietrisiko te ondersoek. ' $n$ Verteenwoordigende steekproef van 250 swak kredietrisikokliènte en $\mathbf{2 5 0}$ goeie kredietrisikokliënte is in die onderhawige ondersoek gebruik. 'n Meervoudige stapsgewyse regressieontleding sowel as 'n meervoudige stapsgewyse diskriminantontleding is uitgevoer. Nege biografiese veranderlikes is geïdentifiseer wat ongeveer $16 \%$ van die variansie van kredietrisiko verklaar.

S.-Afr. Tyoskr. Bedrytsl. 1983, 14: 166-171

Prof. P.L.S. Ackermann"

Skool vir Bedryfsleiding, Universiteit van Suid-Afrika, Posbus 392, Pretoria 0001, Republiek van Suid-Afrika

W.P. Jansen van Rensburg

Trust Bank Hoofkantoor, Johannesburg 2001, Republiek van Suid-Afrika

-Aan wie kortespondensie gerig moet word

\section{Inleidende corsig}

Gedurende die afgelope aantal jare is daar 'n toenemende belangstelling in die voorspelling van kredietrisiko te bespeur. Die ontwikkeling van numeriese gewigtoekenningstelsels en die meer wetenskaplike voorspellingsmodelle, het toenemend belangrik geword. Banke en ander finansiele instellings word voortdurend gekonfronteer met die probleem om potensieel suksesvolle kredietrisikokliënte, reeds in die aansoekstadium, te selekteer. Vir baie jare word daar reeds gesoek na voorspellers van suksesvolle, of anders gestel, goeie kredietrisikokliënte.

Met 'n steeds snel stygende bevolkingsaanwas, groter koopkrag en welvarendheid van die bevolking, is dit vanselfsprekend dat die plaaslike bankwese, bouverenigings en ander finansiële instellings in die komende jare ' $n$ al hoe belangriker rol in die finansiëringsbehoeftees van die algemene publiek sal moet vervul. Namate die lewenspeil van die bevolking in die Republiek van Suid-Afrika styg, sal baie meer persone finansiële dienste benodig. Die finansiële diensindustrie in die Republiek van Suid-Afrika, vorm 'n wesentlike deel van die totale ekonomie en het sedert 1976 'n snelle groei in sekere sektore soos byvoorbeeld die algemene bankwese, handelsbankwese en bouverenigingswese in besonder, openbaar. Finansiële dienste kan met reg beskou word as een van die belangrikste dienste wat in die Republiek van Suid-Afrika 'gekoop' word. Hietdie dienste sluit die uitleen van geld, beleggingsdienste en die verskaffing van spaardienste in. Die finansiële diensindustrie bestaan uit die volgende 13 komponente, waarvan enkele semi-staatsbeheerde instellings is: handelsbanke, bouverenigings, langtermynversekeringsmaatskappye, algemene banke, private pensioenen voorsorgfondse, aksepbanke, korttermynversekeringsmaatskappye, staatskuldkommissarisse, Land-en Landboubank van Suid-Afrika, Nasionale Finansiekorporasie (N.F.K.), diskontohuise, effekte-trusts en ander private finansieringsmaatskappye.

Handelsbanke se bates het vanaf 1975 tot 1981 met $139,4 \%$ gegroei (R8130m tot R19487m), terwyl algemene banke gedurende dieselfde tydperk 'n styging van $235,6 \%$ gehad het (R3461 m tot R11616m). ${ }^{a}$ Algemene banke se rol in die finansiële diensindustrie word steeds groter en die skrywers is van mening dat algemene banke in die volgende dekade, die tweede vlak naas handelsbanke, in die tinansiële diensindustrie in die Republiek van Suid-Afrika, kan inneem. Voorskotte en nielikwiede diskonteringe vorm die vernaamste deel van die totale bates van algemene banke, naamlik $\mathrm{R} 8072 \mathrm{~m}$, wat $69,5 \%$ verteenwoordig. Die vraag ontstaan nou: Waaruit bestaan hier- 
die belangrike komponent in die bates van algemene banke? Voorskotte en nie-likwiede diskonteringe word saamgestel uit: nie-likwiede wissels verdiskonteer of aangekoop (R64m I)esember 1981), huurkoopdiskonteringe en voorskotte (R4115m Desember 1981), handelsware-huurkontrakte (R2376m Desember 1981), ander lenings en voorskotte (R1517m Desember 1981)."

Gesamentlik is huurkoopdiskonteringe en handelswarehuurkontrakte dus $\mathrm{R} 6491 \mathrm{~m}$, wat $80,4 \%$ van voorskotte en nielikwiede disk onteringe en 55,9\% van die totale bates van algemene banke, op 31 Desember 1981, verteenwoordig. Huurkoopdiskonteringe en handelsware-huurkontrakte se styging vanaf 1975 tot 1981 , was $467,9 \%$ en het die grootste enkele bydrac tot die totale styging in bates van algemene banke gelewer. Die druk op algemene banke tot kredietverlening in terme van huurkoopdiskonteringe en handelsware-huurkontrakfinansiering, het veral gedurende die afgelope drie jaar aansienlik toegeneem. Op 31 Desember 1978 was die totale bedrag op dié wyse uitgeleen, R2120m, terwyl dit op 31 Desember 1981 reeds R6491 „11 beloop het. 'n Toename van 206,7\% oor dic laaste drie jaar to 31 Desember 1981, alleen.

\section{Doel van die ondersoek}

Die doel van die ondersoek is om die belangrikheid van biografiese veranderlikes as voorspellers van kredietrisiko te ondersoek. Daar word gepoog om te bepaal of die groot klem wat algemeen op sekere biografiese gegewens by kredietverlening, gelê word, geregverdig is. Meer spesifiek is die doel van die ondersoek om biografiese veranderlikes te identifiseer wat, reeds in die aansoekstadium van kredietverlening deur algemene banke, sal kan bepaal of die aansoeker 'n potensièle swak of goeie kredietrisiko vir die bankinstelling sal wees. Die ondersoek sal hoofsaaklik eksploratief van aard wees en het dit nie ten doel om bevestigende resultate op te lewer nie, maar sal eerder poog om 'n grondslag daar te stel vir verdere navorsing.

Die ondersoek handel oor algemene banke en is slegs beperk tot individucle blanke kliënte. Vanweë dic heterogene bevolkingsamestelling en gevolglike kulturele verskille, tesame met metodologiese oorwegings, is besluit om nie ander bevolkingsgroepe in die ondersoek in te sluit nie.

\section{Noodsaaklikheid van die ondersoek}

Huurkoopdiskonteringe en handelsware-huurkontrakte het vanaf R1143m in 1976 gegroei to R6491m in 1981, 'n styging van meer as $400 \%$ in ses jaar. Dit word algemeen aanvaar dat die blanke bevolking grootliks hierdie substansiële styging in kredietverlening veroorsaak het, maar is die verwagting dat ander bevolkingsgroepe se sterker toetrede tot die huurkoopdiskonteringe- en handelsware-huurkontraktemark, vanweë hul beter verdienstes, in die komende jare ook 'n groter rol in die verdere groeipotensiaal van algemene banke, sal vervul. Kredietrisiko's en hoe om dit te bekamp het vanweë die groter kredietverlening deur algemene banke, in 'n al hoe groter probleemarea ontwikkel.

Indien $0,5 \%$ van algemene banke se totale voorskotte en diskonteringe afgeskryf sou word as onverhaalbaar - dit is die algemene aanvaarbare norm - beteken dit dat ten minste $\mathrm{R} 40,36$ miljoen in 1981 as verlies aan algemene banke toegedeel kon word ten opsigte van kredietrisiko's aanvaar en ontwikkel tot uiteindelike afskrywing as onverhaalbare skulde. Indien daar op wetenskaplike wyse bewese riglyne gevind sou kon word om, reeds by die aansoekstadium vir krediet, te bepaal watter aansoeke in moontlike goeie of swak risiko's sal ontaard, kan die besparing in terme van verliesbekamping deur minder afskrywings, by algemene banke alleen, moontlik etlike miljoene rand per jaar beloop.

\section{Literatuuroorsig}

Die literatuur oor hierdie onderwerp, wat Suid-Afrika betref, is baie beperk, terwyl veral die Verenigde State van Amerika, Kanada en Brittanje se literatuur omvangryk is. Die doel is nie hier om 'n volledige uiteensetting van die betrokke literatuur te gee nie, maar eerder om na enkele relevante ondersoeke te verwys.

\section{Numeriese gewigtoekenningstelsels}

In die tydperk 1930 tot 1960 het bankinstellings hoofsaaklik op persoonlike onderhoudvoering met kliënte, wie behoefte aan krediet gehad het, staatgemaak. Bankbestuurders, rekenmeesters, kredietbestuurders en ander keuringsamptenare het grootliks hul eie subjektiewe oordeel gebruik en daarop hul besluite gebaseer.

$\mathrm{Na} 1960$ is tot 'n groter mate gebruik gemaak van ander hulpmiddele by die toestaan van krediet, alhoewel die oordeel van die keuringsamptenaar steeds die beslissende rol gespeel het. Navorsers, soos byvoorbeeld Meyers en Forgy;' Zaegel; Bartels; ${ }^{3}$ Savery; ${ }^{4}$ Capon; $;$ het gedurende hierdie tydvak navorsingstukke dic lig laat sien, waarin arbitrêre numeriese gewigtoekenningstelsels as hulpmiddel by kredietverlening sterk aanbeveel of verwerp is.

Capon ${ }^{6}$ stel dat die grootste enkele gevaar verbonde aan 'n numeriese gewigtockenningstelsel, die moontlikheid van diskriminasic teen goeie kredietrisiko's is. 'n Numeriese gewigtoekenningstelsel word ontwikkel deur van werklike goeie en swak kredietrisiko's uit die verlede gebruik te maak, dit te ontleed en te evalueer en dan met gewigte te beswaar. Beroep, ouderdom, dienstydperk by werkgewer en tydperk woonagtig by huisadres, was van die belangrikste veranderlikes wat aan gewigtockenning onderwerp is. Numeriese gewigtoekenningstelsels isoleer volgens Capon ${ }^{7}$ die keuringsamptenaar en kan laasgenoemde sy eie moontlike swak oordeel verberg agter die banier van objektiwiteit.

Statistiese tegnieke wat by die voorspelling van kredietrisiko gebruik word

Gedurende die afgelope dekade het finansiële instellings toenemend gehoor begin gee aan navorsers se pleidooie vir die gebruikmaking van voorspellingstegnieke, gegrond op erkende statistiese en wiskundige beginsels. Die uitgangspunt was dat hierdie voorspellingstegnieke meer wetenskaplik van aard was, teenoor die arbitrêre gewigtoekenningstelsels van vroeër. Uit die literatuur blyk dit dat meervoudige regressie- en diskriminanttegnieke in die meeste ondersoeke, waar voorspellings op grond van biografiese veranderlikes gemaak word, gebruik word. Verskeie navorsers (bv. Orgler; ${ }^{8}$ Long \& McConnel; ${ }^{9}$ Scheer; ${ }^{10}$ Eisenbeis ${ }^{11}$ \& Grablowsky ${ }^{12}$ ) het bydraes gelewer tot die ontwikkeling van meer wetenskaplike voorspellingsmetodes van kredietrisiko. Navorsers is dit oor die algemeen eens dat die menslike faktor met betrekking tot oordeel by keuring van goeie of swak kredietrisiko nooit heeltemal uitgeskakel kan word nie. Deur gebruikmaking van 'n wetenskaplike goedontwikkelde kredietevaluerings- of voorspellingsmodel ('credit scoring model') kan menslike oordeelsfoute egter beperk word.

Biografiese veranderlikes as voorspellers van krediet-risiko

Sedert die Eerste Wêreldoorlog is daar in toenemende mate 
van biografiese data gebruik gemaak om sukses of mislukkings op verskeie terreine te voorspel (Levine \& Zachert). ${ }^{13}$ In die periode tussen die twee wêreldoorloë is beduidende verbande tussen verskeie biografiese veranderlikes en sukses of mislukking van studente, verkoopspersoneel, bedryfs- en militêre spesialiste, gerapporteer. Hierdie tendens het tydens die Tweede Wêldoorlog en daarna voortgeduur. Navorsers op die tertein van die voorspelling van kredietrisiko van potensiële of bestaande kliënte van finansiële instellings, het dan ook gaandeweg begin gebruik maak van biografiese veranderlikes op soek na statisties beduidende verbande tussen verskeie veranderlikes en kredietrisiko. Onder hierdie navorsers ressorteer Savery; ${ }^{14}$ Tabor; ${ }^{15}$ Sexton; ${ }^{16}$ Brady; ${ }^{17}$ Grablowsky en Talley. ${ }^{18}$

\section{Biografiese verandertikes wat in die onderhawige onder- soek ingesluit word}

Vir die doeleindes van die onderhawige ondersoek is die volgende biografiese veranderlikes (as onafhanklike veranderlikes) gebruik:

huwelikstatus, aantal afhanklikes, ouderdom, geslag, beroepsektor, bruto inkomste, tydperk werksaam by huidige werkgewer, tydperk woonagtig by huidige adres, besitter van vaste eiendom, besit van 'n telefoon by woonplek, besit van bankrekening, totale laste as persentasie van totale bates, doel van lening, huidige voettuig beswaar, afbetalingstydperk, jaarlikse uitgawes, balans verskuldig as persentasie van hoofskuld by aangaan van die skuld, vorige kredietverwysings (slegs finansiële instellings), vorige vonnisse, ouderdom van artikel gefinansier, goedgekeurde handelaar, area woonagtig, bestaande of nuwe kliënt en afbetalingstussenposes.

\section{Probleemstelling}

Die probleem in hierdie ondersoek handel oor biografiese veranderlikes wat ' $n$ rol by kredietrisiko vervul. Die volgende probleme kan meer spesifiek geformuleer word:

- Watter biografiese veranderlike verklaar die grootste proporsie variansie van kredietrisiko? Met ander woorde watter veranderlike is die belangrikste voorspeller van kredietrisiko?

- Sal dié enkele veranderlike, tesame met 'n beswaarde kombinasie van bepaalde biografiese veranderlikes, nie 'n groter proporsie van die variansie van kredietrisiko verklaar as die enkele veranderlike nie? Wat is die relatiewe bydrae van die verskeie veranderlikes?

- Kan swak risikokliënte van goeie risikokliënte op grond van 'n beswaarde kombinasie van bepaalde biografiese veranderlikes, onderskei word?

- Word die grootste proporsie variansie van kredietrisiko nie bepaal deur ander veranderlikes (nie biografiese) wat normaalweg nie by die kredietaansoekvorm ingesluit word nie?

\section{Navorsingsontwerp en ontleding \\ Steekproef}

Die steekproef bestaan uit 500 kliënte van 'n algemene bankinstelling, waarvan 250 swak kredietrisiko's en 250 goeie kredietrisiko's. Die kredietrekenings by die steekproef ingesluit, het almal sedert Junie 1982 volopbetaald geraak en is ewekansig uit die lêers van die bankinstelling verkry. Die geografiese verspreiding strek oor die hele Republiek van Suid-Afrika.

\section{Meetinstrument}

Die metinstrument wat in die ondersoek gebruik is, is 'n biografiese vraelys, wat onder persoonlike kontrole van die onderskeie bestuurders van banktakkantore versprei is. Ten einde die betroubaarheid van die meetinstrument te probeer verhoog, is die bestuurders van takkantore versoek om persoonlik in 'n toesighoudende hoedanigheid op te tree.

Die geldigheid van al die inligting versamel kan moeilik positief bevestig word, omdat aansoekers om kredit, moontlik sekere inligting op aansoek vorms opsetlik foutief kan verstrek het, byvoorbeeld jaarlikse inkomste- en uitgawes, waarde van bates en laste, weglating van moontlike swakkredietverwysings. Bykans alle aansoekvorms bevat egter 'n klousule onderaan, waarin die aansoeker verklaar dat alle inligting verstrek, die waarheid is en 'n juiste weergawe is van sy werklike situasie.

Waar ontbrekende inligting by ' $n$ individuele steekproefrekening voorgekom het, is die betrokke steekproefrekening in geheel uit die totale steekproef weggelaat.

\section{Kwantifisering van veranderlikes}

By die kwantifisering van verskeie van die veranderlikes, word van fopveranderlikes ('dummy variables') gebruik gemaak. Die kwantifisering van die afhanklike veranderlike, kredietrisiko, is byvoorbeeld as volg gedoen:

$\mathrm{Y}=1$ indien respondent ' $\mathrm{n}$ goeie kredietrisiko is;

$\mathrm{Y}=0$ indien respondent 'n swak kredietrisiko is.

\section{Statistiese tegnieke}

Navorsers het van verskillende statistiese tegnieke gebruik gemaak om kredietrisiko te voorspel. Die meeste navorsers hat, veral sedert 1975, op meervoudige regressie-ontleding of diskriminantontleding ('n spesiale geval van meervoudige regressie-ontleding in geval van twee groepe) gekonsentreer. Skrywers soos Orgler; $;^{19}$ Eisenbeis; ${ }^{20}$ Scheer $^{21}$ en Grablowsky en Talley ${ }^{22}$ ressorteer onder hierdie navorsers.

Die eerste probleem in die onderhawige ondersoek het betrekking op die vraag watter biografiese veranderlike die grootste proporsie variansie van kredietrisiko verklaar. Om 'n antwoord op hierdie vraag te probeer vind, word van stapsgewyse meervoudige regressie-ontleding gebruik gemaak. Die rekenaarprogram wat in die geval gebruik is, is die standaard BMDP $^{23}$ stapsgewyse-regressieprogram.

Die tweede probleem in hierdie ondersoek handel oor die variansie van kredietrisiko wat deur 'n beswaarde kombinasie van biografiese veranderlikes verklaar word, asook die relatiewe bydraes wat deur elke veranderlike gelewer word. Soos in die geval van die eerste probleem, word hier ook van meervoudige stapsgewyse-regressie-ontleding gebruik gemaak.

Die derde probleem van die ondersoek verwys na die vraag of swak risikokliënte van goeie risikokliënte op grond van 'n beswaarde kombinasie van bepaalde biografiese veranderlikes onderskei kan word. Om hierdie probleem op te los, is daar van stapsgewyse-regressie-ontleding sowel as stapsgewyse diskriminantontleding gebruik gemaak. Die diskriminantontledingsprogram is die standaard $\mathrm{BMDP}^{24}$ stapsgewyse diskriminantontledingsprogram.

Die laaste probleem in hierdie ondersoek het betrekking op die relatiewe belangrikheid wat ander veranderlikes wat normaalweg nie by die kredietaansoekvorm ingesluit word nie, uitoefen op kredietrisiko. Die antwoord op hierdie probleem sal voortspruit uit die bevindinge ten opsigte van die relatiewe belangrikheid van biografiese veranderlikes by die voorspelling van kredietrisiko (probleem twee).

\footnotetext{
${ }^{b}$ Vir operasionele definisies en kwantifisering van veranderlikes, sien Van Rensburg, Die voorspelling van kredietrisiko met behulp van biografiese veranderlikes, ongepubliseerde M.Com.-verhandeling, Unisa, 1983.
} 
Tabol 1 Veranderlikes deur stapsgewyse regressie-ontleding geselekteer

\begin{tabular}{|c|c|c|c|c|}
\hline Stap & Veranderlikes geselekteer & $\begin{array}{c}\text { Standaard } \\
\text { skattingsfout }\end{array}$ & $\begin{array}{l}\text { Meervoudige } \\
\text { korrelasie } \\
\quad(R)\end{array}$ & $\begin{array}{l}\text { Proporsie } \\
\text { variansie } \\
\text { verklaar } \\
\quad\left(R^{2}\right)\end{array}$ \\
\hline 1 & Huur & 0,4935 & 0,1725 & 0,0298 \\
\hline 2 & Huur, ouderdom van artikel & 0,4840 & 0,2622 & 0,0688 \\
\hline 3 & Huur, ouderdom van artikel, besit van telefoon & 0,4774 & 0.3090 & 0.0955 \\
\hline 4 & Huur, ouderdom van artikel, besit van telefoon, besit van bankrekening & 0,4726 & 0.3397 & 0,1154 \\
\hline 5 & $\begin{array}{l}\text { Huur, ouderdom van artikel, besit van telefoon, besit bankrekening. } \\
\text { uitstaande balans as persentasie van koopprys }\end{array}$ & 0,4699 & 0.3571 & 0,1275 \\
\hline 6 & $\begin{array}{l}\text { Huur, ouderdom van artikel, besit van telefoon, besit bankrekening. } \\
\text { balans as persentasie koopprys, swak kredietverwysings }\end{array}$ & 0,4672 & 0.3730 & 0,1391 \\
\hline 7 & $\begin{array}{l}\text { Huur, ouderdom van artikel, besit van telefoon, besit bankrekening, } \\
\text { balans as persentasie koopprys, swak verwysings, privaatsektor-beroep }\end{array}$ & 0,4653 & 0,3846 & 0,1479 \\
\hline 8 & $\begin{array}{l}\text { Huur, ouderdom van artikel, besit van telefoon, besit bankrekening, } \\
\text { balans as persentasie koopprys, swak verwysings, privaatsektor-beroep, } \\
\text { stedelike-area }\end{array}$ & 0,4636 & 0,3945 & 0,1557 \\
\hline 9 & $\begin{array}{l}\text { Huur, ouderdom van artikel, besit van telefoon, besit bankrekening, } \\
\text { balans as persentasie koopprys, swak verwysings, privaat rektor-beroep, } \\
\text { stedelike-area, aantal afhanklikes }\end{array}$ & 0,4617 & 0,4056 & 0,1645 \\
\hline
\end{tabular}

\section{Resultate}

\section{Stapsgewyse regressie-ontleding}

In Tabel 1 word die standaardskattingsfout, meervoudige korrelasie $(R)$ en proporsie variansie $\left(R^{2}\right)$ wat by elke stap in die stapsgewyse regressie-ontleding verklaar word, aangedui.

Uit Tabel 1 blyk dit verder dat die volgende veranderlikes agtereenvolgens geselekteer is:

huur, ouderdom van artikel, besit van telefoon by woonadres. besit van bankrekening, uitstaande balans as persentasie van koopprys, swak kredietverwysings by finansiële instellings, werksaam in privaatsektor, woonagtig in stedelike area en aantal afhanklikes. Die veranderlikes geselekteer, verklaar $16,45 \%$ van die variansie van kredietrisiko.

In Tabel 2 word die regressiekoëfisiënte, standaardfoute van die regressiekoëffisiënte, beta-koëffisiënte, $F$-waardes vir die bepaling van die beduidendheid van die regressiekoëffisiënte, aangedui. Die konstante term verskyn onderaan dié tabel.

Die negatiewe regressiekoëffisiënte in Tabel 2 kan toegeskryf word aan die wyse waarop die veranderlikes gekwantifiseer is. Die kwantifisering is arbitrêr gedoen.

\section{Stapsgewyse diskriminantontleding}

In Tabel 3 word die diskriminantfunksie-koëffisiënte wat in hierdie studie afgelei is, aangedui. Soos verwag kan word, is dieselfde veranderlikes agtereenvolgens in dieselfde volgorde geselekteer as by die stapsgewyse regressie-ontleding (kyk Tabel 1 vir volgorde).

\section{Klassifikasiematriks gebasseer op diskriminantfunksie}

Die klassifikasiematriks (klassifikasietabel) is afgelei met behulp van die verkreë diskriminantfunksie (Tabet 3). Die klassifikasiematriks word in Tabel 4 getoon. Hieruit volg dat $68 \%$ van die swak risikokliënte en $70 \%$ van die goeie risikokliënte korrek geklassifiseer is.

Tabel 5 toon dat ongeveer $66 \%$ van die swak risiko's en 69\% van die goeie risiko's met behulp van die 'Jack-knifed'metode korrek geklassifiseer is.

\section{Klassifikasiematriks met behulp van die 'Jack-knifed'-metode bepaal}

Ten einde die geldigheid van die diskriminantfunksie te toets, is daar gebruik gemaak van die 'Jack-knifed'-metode.'

\section{Interpretasies}

Enkele veranderlike wat die grootste proporsie varian. sie van kredietrisiko verklaar

Volgens Tabel 1 blyk dit dat die enkele veranderlike huurtransaksie die grootste proporsie variansie van kredietrisiko verklaar. Hierdie veranderlike verklaar ongeveer $3 \%$ van die variansie van kredietrisiko.

\section{Relatiewe bydrae van ander geselekteerde veranderli-kes}

Die relatiewe bydrae van die ander geselekteerde veranderlikes, word duidelik in Tabel 1 weerspieël. Die veranderlike eerste geselekteer, tesame met ' $n$ beswaarde kombinasie van biografiese veranderlikes, verklaar 'n groter proporsie van die variansie van kredietrisiko, naamlik $16,45 \%$.

\section{Onderskeid tussen goeie risikokliënte en swak risiko-kliënte}

Uit Tabelle 3, 4 en 5 kan gekonkludeer word dat swak risikokliënte van goeie risikokliënte op grond van 'n beswaarde kombinasie van biografiese veranderlikes, onderskei kan word. Hierdie resultaat is beduidend op die 0,001 vlak.

Variansie van kredietrisiko deur veranderlikes verklaar, wat normaalweg nie by die kredietaansoekvorm ingesluit is nie

Soos reeds aangedui, word slegs ongeveer $16 \%$ van die variansie van kredietrisiko deur die geselekteerde veranderlikes ver-

\footnotetext{
'Vir 'n bespreking van die 'Jack-knifed'-metode, sien BMDP-77: Engelman, L., Frane, J.W. \& Jennrich, R.I. Biomedical Computer Programs P-series, Berkeley, Los Angeles, London: University of California Press, p.711.
} 
Tabol 2 Stapsgewyse regressie-ontleding op biografiese veranderlikes

\begin{tabular}{|c|c|c|c|c|c|}
\hline Beskrywing van veranderlike & Regressiekoëffisiënt & $\begin{array}{l}\text { Standaard fout } \\
\text { van koëffisiënt }\end{array}$ & Betakoëffisiënt & $\theta$-waarde & $\begin{array}{c}\text { Vlak van } \\
\text { beduidendheid }\end{array}$ \\
\hline Aantal afhanklikes & 0,031 & 0,014 & 0,098 & 5,21 & 0,001 \\
\hline Besit van telefoon & 0,125 & 0,046 & 0,116 & 7,32 & 0,001 \\
\hline Besit van bankrekening & 0,237 & 0,069 & 0,145 & 11,99 & 0,001 \\
\hline Huur & $-0,281$ & 0,061 & 0,215 & 21,29 & 0,001 \\
\hline Balans as persentasie van koopprys & $-0,003$ & 0,001 & $-0,124$ & 7,68 & 0,001 \\
\hline Swak kredietverwysing & $-0,270$ & 0,128 & $-0,089$ & 4,44 & 0,001 \\
\hline Ouderdom van artikel & $-0,051$ & 0,011 & $-0,205$ & 21,87 & 0,001 \\
\hline Stedelike gebied & 0,104 & 0,045 & 0,099 & 5,35 & 0,001 \\
\hline Werksaam in privaatsektor & $-0,115$ & 0,043 & $-0,113$ & 7,07 & 0,001 \\
\hline
\end{tabular}

Tabel 3 Diskriminantfunksie-koëffisiënte vir swak en goeie kredietrisiko's

\begin{tabular}{|c|c|c|c|c|c|}
\hline Beskrywing van veranderlike & Swak risiko's & Goeie risiko's & $\mathbf{b}_{\mathrm{j}}$ & $F$-waarde & $\begin{array}{c}\text { Vlak van } \\
\text { beduidendheid }\end{array}$ \\
\hline Aantal afhanklikes & 0,94278 & 1,09174 & 0,14896 & 5,21 & 0,001 \\
\hline Besit van telefoon & 3,97715 & 3,67414 & 0,59699 & 7,32 & 0,001 \\
\hline Besit van bankrekening & 9,15705 & 10,28910 & 1,13205 & 11,99 & 0,001 \\
\hline Huurtransaksie & $-2,35770$ & $-3,69723$ & $-1,33953$ & 21,29 & 0,001 \\
\hline Balans as persentasie van koopprys & 0,29044 & 0,27715 & $-0,01329$ & 7,68 & 0,001 \\
\hline Swak kredietverwysing & 5,18301 & 3,89476 & $-1,28825$ & 4,44 & 0,001 \\
\hline Ouderom van artikel & 1,04920 & 0,80764 & $-0,24156$ & 21,87 & 0,001 \\
\hline Stedelike gebied & 2,49980 & 2,99370 & 0,49390 & 5,35 & 0,001 \\
\hline Werksaam in privaatsektor & 1,98941 & 1,44148 & $-0,54793$ & 7,07 & 0,001 \\
\hline Konstante & $-25,69531$ & $-25,18097$ & $+0,51434$ & & \\
\hline
\end{tabular}

Tabel 4 Klassifikasiematriks gebasseer op die diskriminantfunksie

\begin{tabular}{lccc}
\hline Groep & $\begin{array}{c}\text { Persentasie korrek } \\
\text { geklassifiseer }\end{array}$ & $\begin{array}{c}\text { Swak } \\
\text { risiko }\end{array}$ & $\begin{array}{c}\text { Goeie } \\
\text { risiko }\end{array}$ \\
\hline Swak risiko & $\mathbf{6 8 , 0 0}$ & $\mathbf{1 7 0}$ & $\mathbf{8 0}$ \\
Goeie risiko & 70,00 & 75 & 175 \\
Totaal & 69,00 & 245 & 255 \\
\hline
\end{tabular}

Tabel 5 Klassifikasiematriks gebasseer op die 'Jack-knifed'-metode

\begin{tabular}{lccc}
\hline Groep & $\begin{array}{c}\text { Persentasie korrek } \\
\text { geklassifiseer }\end{array}$ & $\begin{array}{c}\text { Swak } \\
\text { risiko }\end{array}$ & $\begin{array}{c}\text { Goeie } \\
\text { risiko }\end{array}$ \\
\hline Swak risiko & 66,40 & 170 & 80 \\
Goeie risiko & 69,20 & 77 & 173 \\
Totaal & 67,80 & 243 & 257 \\
\hline
\end{tabular}

klaar. 'n Groot proporsie van die variansie van kredietrisiko, naamlik $84 \%$, word deur ander veranderlikes, wat normaalweg nie by die kredietaansoekvorm ingesluit is nie, verklaar.

\section{Bespreking}

Soos reeds vermeld word slegs ongeveer $16 \%$ van die variansie van kredietrisiko deur 'n beswaarde kombinasie van bepaalde biografiese veranderlikes verklaar. 'n Aansienlike proporsie van die variansie van kredietrisiko, naamlik $84 \%$, word deur ander veranderlikes, wat normaalweg nie by die kredietaansoekvorm ingesluit is nie, verklaar.
Die resultate van die ondersoek suggereer dat te veel klem deur bankinstellings op die inligting wat normaalweg deur aansoekers op aansoekvorms verstrek, gelê word. Die ander veranderlikes waarna verwys word, sluit moontlik veranderlikes in soos byvoorbeeld:

interverhouding tussen kredietbeheeramptenaar en kliënt (hantering van kliënt), opvolgingsmetodes om agterstallige bedrae in te vorder en opvoedingstaak van bankinstellings met betrekking tot swakbetalers.

Ten einde meer lig op hierdie komplekse probleem te werp, sal meer in diepte navorsing vereis word, wat buite die bestek van die onderhawige ondersoek val.

\section{Gevolgtrekkings}

Meer veranderlike statistiese tegnieke soos regressie- en diskriminantontleding kan met vrug as hulpmiddel by die voorspelling van kredietrisiko by bankinstellings gebruik word. Dit moet egter beklemtoon word dat die statistiese tegnieke gesien word as slegs 'n hulpmiddel en nie die menslike betrokkenheid kan vervang nie. Statistiese modelle vir een instelling ontwikkel kan nie noodwendig sondermeer vir 'n ander instelling gebruik word nie.

Biografiese veranderlikes kan gebruik word om kredietrisiko te voorspel, maar in die lig daarvan dat slegs $16 \%$ van die variansie van kredietrisiko verklaar is in die ondersoek, moet die beperktheid daarvan egter beklemtoon word.

'n Aansienlike proporsie variansie van kredietrisiko, naamlik $\mathbf{8 4 \%}$ word verklaar deur ander veranderlikes wat nie by die ondersoek ingesluit is nie. Dit volg dus dat keuring deur bankinstellings, gegrond op die inligting wat normaalweg in aansoekvorms voorkom, moontlik riskant kan wees. 


\section{Aanbevelings}

'n Soortgelyke ondersoek as die onderhawige kan ook met korporatiewe kliënte in plaas van individue as kliënte, uitgevoer word.

Navorsing behoort gedoen te word oor die totale 'filosofie' van kredietbeheer binne die organisasie self vanweë die groot proporsie onverklaarde variansie van kredietrisiko in hierdie ondersoek gevind.

Gesien in die lig van die toenemende welvarendheid onder die swart bevolking in die Republiek van Suid-Afrika, kan dit raadsaam wees om met die oog op die toekoms 'n soortgelyke ondersoek onder swart kliënte van stapel te stuur.

\section{Summary}

The objective of this study was to investigate the importance of biographical variables as predictors of credit risk. An attempt was made to determine whether the strong emphasis which is generally placed on certain biographical data when an application for credit is considered, is justified. More specifically, the objective was to identify specific biographical variables, to quantify them and to investigate their relative importance in the prediction of credit risk.

A representative sample of 250 bad credit risk clients and 250 good credit risk clients of a general bank was used in the study. Their geographical distribution covers the whole of the Republic of South Africa.

A biographical questionnaire was employed as the measuring instrument. Dummy variables were used in the quantification of some of the variables.

A multiple stepwise regression analysis and a multiple stepwise discriminant analysis were performed on the data.

Nine biographical variables, which explain approximately $16 \%$ of the variance of credit risk, were identified.

The following conclusions were drawn:

- Multiple statistical techniques, such as regression and discriminant analysis, can be employed as a valuable aid in the prediction of credit risk.

- Biographical variables can be used to predict credit risk, but the limitations must be realized.

- A substantial proportion of the variance of credit risk, namely $84 \%$, is explained by variables not included in this study.

\section{Verwysings}

1. Myers, J.H. \& Forgy, E.W. The development of numerical credit evaluation systems. Am. Stat. Assoc. J. September 1963, p.799.

2. Zaegel, R.J. A point rating system for evaluating customers. The Credit World, Oct. 1963, p.9.

3. Bartels, R. Credit Management, New York: Ronald Press Co. 1967, chapters $20-23$

4. Savery, B.J. The analysis of Numerical Points Systems in the Credit Screening Process, M.Sc. thesis, University of Bradford, 1974.

5. Capon, N. Discrimination in screening credit application - Harv. Bus. Rev., vol.56, May/June 1978, p.8.

6. Ibid.

7. Ibid.

8. Ogler, Y.E. A credit scoring model for commercial loans, Management Science in Banking, Cohen, K.J. \& Gibson, S. pp.323-334. The Journal of Money, Credit and Banking, vol.2, no. 4 (Nov. 1970), p.435.

9. Long, M.S. \& McConnell. Credit scoring systems aids second mortgage Banker. Mortgage Banker, vol.37, July, p.29 foll.

10. Scheer, F.C. Using statistics to forecast default. Credit and Financial Management, vol.79, Jan. 1977, p.28 foll

11. Eisenbeis, R.A. Selection and Disclosure of Reasons for Adverse Action in Credit-granting Systems. Federal Reserve Bull., vol.66, Sept. 1980 , p. 727.

12. Grablowsky, B.J. \& Talley, W.K. Probit and discriminant functions for classifying credit applicants: a comparison. Journal of Economics and Business, vol.33, Spring/Summer 1981, p.254.

13. Levine, A.S. \& Zachert, V. (1951). Use of biographical inventory in the Air Force Classification Program. J. App. Psychol., 1951, p.35, p. 241

14. Savery, B.J. Numerical points systems in credit screening. Managerial Finance, vol.2, no.3, 1976, p.180.

15. Tabor, J.S. \& Bowers, J.S. Factors determining credit worthiness of low income consumers. Journal of Consumer Affairs, vol.11, $1977, p .43$.

16. Sexton, D.E. Determining good and bad Credit Risks among High- and Low-Income Families. Journal of Business, vol.50, April 1977, p.236.

17. Brady, T.F. Changes in banking lending practices. Fed. Res. Bull., vol.65, no.10. Oct. 1979, p.797.

18. Grabowsky \& Talley, op. cit.

19. Orgler, op. cit.

20. Eisenbeis, op. cit.

21. Scheer, op. cit

22. Grablowsky \& Talley, op. cit.

23. Dixon, W.J., Brown, M.B., Engelman, L., Frane, J.W. \& Jennrich, R.I. Biomedical Computer Program P-series. Berkeley-Los Angeles; London: University of California Press, 1977.

24. Ibid. 